\title{
Prevalence of Human Leukocyte Antigen B27 Positivity and Microbiological Profiles of Patients with Reactive Arthritis - A Cross Sectional Study
}

\author{
T. Jayaprakash ${ }^{1 *}(\mathbb{D})$, K.V. Leela ${ }^{1}$ (D) A.Sundaram ${ }^{2}$ (D), \\ C. Panchapakesa Rajendran ${ }^{3}$ (D) and R. Aparna ${ }^{1}$ (D)
}

${ }^{1}$ Department of Microbiology, SRM Medical College Hospital and Research Centre. Kattankulathur, Chennai 603 203, Tamilnadu, India.

${ }^{2}$ SRM Medical College Hospital and Research Centre. Kattankulathur, Chennai - 603 203. Tamilnadu, India. ${ }^{3}$ Department of Rheumatology, SRM Medical College Hospital and Research Centre. Kattankulathur, Chennai 603 203. Tamilnadu, India.

\begin{abstract}
The present study aims to determine the spectrum of etiological agents and to screen HLA-B27 and, related inflammatory markers in patients presenting with symptoms of Spondyloarthritis(SpA) post diarrhea, which can aid in prompt diagnosis of reactive arthritis (ReA). A total of 903 stool samples of patients presenting with diarrhea were collected and screened with microscopic and culture techniques to identify the etiological agents. Blood samples of patients presenting with both diarrhea and arthritis were collected and subjected to C- reactive protein(CRP), Erythrocyte sedimentation rate(ESR) and Human Leukocyte Antigen B27(HLA-B27) detection tests.Among the total of 903 patients, 20 Salmonella species were isolated. Othergut microbes identified included Escherichia coli 572(63\%), Klebsiella species 126(14\%), Proteus vulgaris 43(5\%), Proteus mirabilis 27(3\%), Citrobacter species and Enterococcus species $\mathbf{8}(1 \%)$, while some of these organisms(3.2\%) caused inflammation resulting in ReA. Parasitic etiology was found in 99 patients, among which the most common parasites include Entamoeba histolytica and hookworm, identified through microscopy. Among the total, 29 patients were found to have symptoms of joint pain with articular and extra articular manifestations, and some associated with HLA-B27.
\end{abstract}

Keywords: Reactive arthritis, HLA-B27, Salmonella spp., Gut microbes, Diarrhea

*Correspondence: jpmicro74@gmail.com; +91 9791252455

(Received: August 04, 2020; accepted: February 19, 2021)

Citation: Jayaprakash T, Leela KV, Sundaram A, Rajendran CP, Aparna R. Prevalence of Human Leukocyte Antigen B27 Positivity and Microbiological Profiles of Patients with Reactive Arthritis - A Cross Sectional Study. J Pure Appl Microbiol. 2021;15(1):382389. doi:10.22207/JPAM.15.1.33

(C) The Author(s) 2021. Open Access. This article is distributed under the terms of the Creative Commons Attribution 4.0 International License which permits unrestricted use, sharing, distribution, and reproduction in any medium, provided you give appropriate credit to the original author(s) and the source, provide a link to the Creative Commons license, and indicate if changes were made. 


\section{INTRODUCTION}

Reactive arthritis(ReA), defined as sterile synovitis, develops after a distant infection and may or may not be HLA-B27 associated. The detection of microbial components in the joints of patients with $\mathrm{ReA}$, has led to the redefinition of ReA as an immune-mediated synovitis. It can result from slow bacterial infections with the presence of immunologic bacterial antigens and/or viable nonculturable bacteria in the intra-articular spaces, produced by metabolically active bacteria residing in the body, usually in the gastrointestinal or urogenital tract [Mustafa Serdar SA ${ }^{1}$, Colmegna I. ${ }^{2}$ ]. The clinical manifestations may include articular sites characterized by asymmetrical inflammation in the axial and peripheral joints and extra-articular manifestations such as urethritis, eye infections, skin rashes, or mucocutaneous manifestations [Schiellerup P. ${ }^{3}$, Connor BA. ${ }^{4}$.

Infections caused by Salmonella, Shigella, or Yersinia have been significantly associated with the risk of ReA, while itis uncommon in infections caused by Campylobacter or E. coli [Schiellerup P. ${ }^{3}$, Ekman P.5]. Other factors such as age, sex, bacterial load, as well as the presence or absence of HLA B27, may also influence the susceptibility for ReA [Schiellerup P. ${ }^{3}$, Ekman P. ${ }^{5}$ ].

Recent studies on ReA have focused on the post-infection complications caused by enteric pathogens such as Escherichia coli,Salmonella species,Campylobacter jejuni, Clostridium difficile, Entamoeba histolytica, Giardia lamblia, and Cryptosporidium [Buret AG. ${ }^{6}$, Keating RM. ${ }^{7}$, Boice JL. ${ }^{8}$, Woo P. ${ }^{9}$, Brocq O. ${ }^{10}$, Meadow ${ }^{11}$, GarciaKutzbach ${ }^{12}$ ] Following an enteric microbial infection, ReA has been reported in $1 \%$ of patients [Rohekar S. ${ }^{13}$ ] to $62 \%$ [Fendler C. ${ }^{14}$ ].

Periodic infections or delivery of bacterial antigen(s)to the joints may directly induce the activation of immune system which may result in the production of antigenic epitopes with crossreactivity. Delivery of bacterial antigens, known as molecular mimicry, may induce the activation of cell-mediated immunity, in particular, cytotoxic $T$ lymphocytes (CTLs), which show reactivity to HLA-B27 and also comprises of protein sequences analogous to those detected in bacteria associated in arthritis. Antibodies with reactivity to HLA-B27 have been detected in patients with arthritis [Harrison ${ }^{15}$, Hannu T. ${ }^{16}$, Ajene AN. ${ }^{17}$ ].
A high degree of genetic polymorphism has been observed in HLA-B27[Khan MA. ${ }^{18}$ ]. The diagnostic markers of enteric pathogens are related to the basic inflammatory markers correlated with the predisposing genetic marker of HLA-B27. It helps to identify the geographical distribution of genetic sub-type variations, where the patients are referred to a tertiary care centre.

\section{MATERIALS AND METHODS}

All the patients with diarrhea, who were admitted to Sri Ramaswamy Memorial Medical College Hospital and Research Centre (SRM $\mathrm{MCH} \& \mathrm{RC}$ ), Kattankulathur, Tamilnadu, between January 2018 and December 2019, were recruited in the study. All patients $\geq 18$ years were made to understand the purpose of the test, assured of the confidentiality of the results, before obtaining the signed consent. Patients who did not have symptoms of spondyloarthritis post-diarrhea; and patients who weren't available for follow up, were excluded from the study. All patients with diarrhea and symptoms of spondyloarthritides were diagnosed by the rheumatologist ( $\mathrm{Dr}$. C Panchapakesa Rajendran) and sent to the laboratory for further investigations. Stool specimens of all the 1108 patients were collected and transported in glucose phosphate broth and processed using culture methods as per CLSI guidelines, by the microbiologist $\left(1^{\text {st }}\right.$ author, Jayaprakash T.).

Within $2 \mathrm{~h}$ of collection, the samples were processed by laboratory technicians. Stool samples were macroscopically observed for the presence of blood and/or mucus, followedby Gram staining using the modified Hucker's method to easily detect the morphology of any bacteria present [Humphries RM. ${ }^{19}$ ]. Direct wet-mount preparation was carried out with the stool samples, by adding 2-3 drops of $0.85 \%$ saline and examined under a $22-22 \mathrm{~mm}$ coverslip to detect motile trophozoites. The iodine-mount method was also used to provide a better contrast to detect the presence of bile-stained eggs. Fecal concentration methods were also used, as mentioned in Garcia LS et al. 2018; the sedimentation technique was performed and observed as wet preparation under the microscope using $10 x$ and $40 x$ objectives, with and without the presence of iodine [Garcia L.S. ${ }^{20}$.

As routine specimen processing, stool 
samples were inoculated in Selenite $\mathrm{F}$ broth, to enrich the salmonella species present. Samples were plated on MacConkey (MAC) media - to differentiate between lactose fermenting and nonlactose fermenting enteropathogens. Selective media such as Xylose Lysine Deoxycholate agar (XLD), and Deoxycholate Citrate agar (DCA) were used - to detect and differentiate the recovery of Salmonella, Shigella species, 5\% Sheep blood agar (SBA) was used - to detect the presence of Vibrio spp., Plesiomonas spp., and Aeromonas spp., [Sanchez-Romero MI (21), S.A. ${ }^{22}$ ].

Phenotypic characteristics of the colonies were noted down and compared their consistency with that of enteric pathogens. Furthermore, the selective colonies were screened using biochemical tests such as, Indole test -to aid in differentiate various Enterobacteriaceae members and between P. mirabilis and P. vulgaris, Mannitol Motility Medium (MMM) - to determine the ability of the bacteria to ferment mannitol, and detect motility of the organisms, Triple Sugar Iron (TSI) test - to detect the production of hydrogen sulfide, gas, and the ability to ferment glucose, lactose and/or sucrose; Christenson's urea agar test - to distinguish Proteus spp. from other enteric bacteria; and Simmons' citrate medium test; to determine the ability of the organisms to use citrate as its sole carbon source, thus differentiating members of Enterobacteriaceae. All the isolates identified were further subjected to antimicrobial susceptibility tests to detect any resistance to the battery of antimicrobials used. All the culture techniques were performed with the quality control strains obtained from American Type Culture Collection (ATCC).

Among the total(1108), 205 patients were excluded as they were not available for follow-up, while the remaining 903 patients with diarrhea were followed up for 3-4 weeks, to check whether they had articular complaints of axial(unilateral or bilateral sacroiliitis, neck pain) and peripheral joints(shoulder, elbow, wrist, finger, thigh, knee, foot, heel and dorsum of foot pain), followed by extra-articular symptoms such as uveitis, and psoriasis. Laboratory evaluation including Human Leukocyte antigen (HLA-B27), C-reactive protein (CRP) and Erythrocyte Sedimentation Rate (ESR) were done in 29 patients who fulfilled the classification criteria for spondyloarthritis by Assessment of Spondyloarthritis International Society(ASAS). There are no universally accepted classification criteria specific for reactive arthritis and may vary with studies.

Blood samples of patients suspected with reactive arthritis ${ }^{29}$ were collected by a phlebotomist under aseptic conditions, $2 \mathrm{ml}$ in ethylenediamine tetraacetic acid(EDTA) tubes and $2 \mathrm{ml}$ in plain blood vacutainers. The EDTA samples were tested for ESR and for the detection of HLA-B27, while the blood collected in plain vacutainers were used to test for CRP using latex

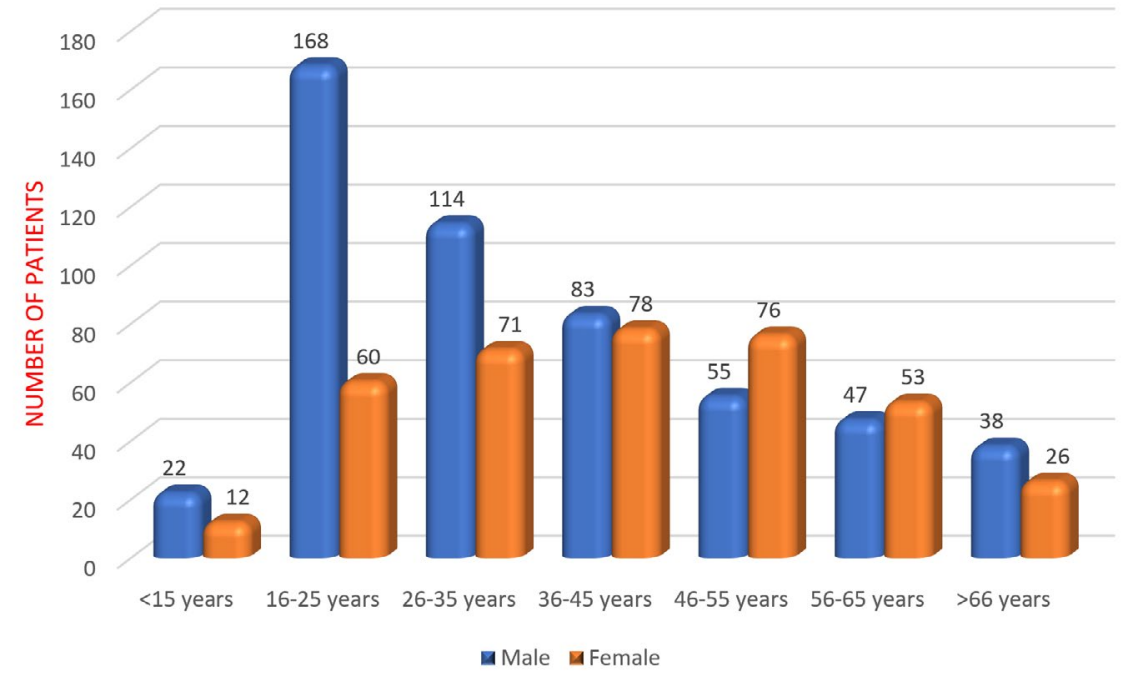

Fig. 1. Distribution of total diarrheal samples by age and gender 
agglutination methods.

HLA-B27 (genetic marker)detection was performed by a microbiologist (Jayaprakash T.) using a Chip based Real-Time PCR (RT-PCR) method, based on the principle of TaqMan assay. DNA extraction from whole blood samples collected from patients in EDTA tubes was performed with Trueprep ${ }^{\circledR}$ AUTO/AUTO v2 Universal Cartridge based Sample Prep Device and Trueprep ${ }^{\circledR}$ AUTO/ AUTO v2 Universal Cartridge based Sample Prep kit, which uses a proprietary matrix enclosed in a cartridge to purify nucleic acid from clinical samples.

The Truenat ${ }^{\text {TM }}$ HLA-B27 chip labelled with patient ID is placed on the chip tray, away from the analyzer, without touching the reaction well. The cap of the microtube containing freeze-dried PCR reagents is removed, and using the filter barrier tip, $6 \mu \mathrm{L}$ of purified DNA is transferred into the microtube. The tube was allowed to stand for 30-60s to get a clear solution. The clear solution $(6 \mu \mathrm{L})$ was dispensed into the reaction well of Truenat $^{\mathrm{TM}}$ HLA-B27 chip, and the test was initiated. At the end of the test run, a result was displayed on the Truelab ${ }^{\circledR}$ analyzer screen showing whether HLA-B27 was "DETECTED" or "NOT DETECTED", along with the threshold cycle value( $\mathrm{Ct}$ value) of the internal positive control(IPC) and the validity of the test.

\section{RESULTS}

Out of 903 cases, there were 527 (58.3\%) males and 376 (41.6\%) females among which 228
(25.2\%) patients belonged to the age group of 1625 years (Fig. 1). Reactive arthritis was present in 29 patients(Fig. 2), out of which 17 (58.6\%) were male and $12(41.3 \%)$ were female. All 29 cases belonged to the age between 16 and 45 years, with the mean age of 31.5 years(Fig. 3).The axial, non-axial (peripheral) and extra-articular clinical manifestation observed in patients with ReA have been tabulated (Table 1).

Bacterial etiology of Salmonella species and parasitic etiology were identified in $20(2.2 \%)$

Table 1. Frequency of clinical manifestations in ReA patients ${ }^{29}$.

\begin{tabular}{ll}
\hline Pain sites $\quad$ No. (\%) \\
\hline
\end{tabular}

\section{Axial articular sites}

Neck pain

$13(45 \%)$

Lower back pain

$12(41 \%)$

Sacroiliitis

$07(24 \%)$

Upper back pain

$06(21 \%)$

Peripheral articular sites

Knee pain

Heel pain

Dactylitis

Shoulder pain

Wrist pain

Ankle pain

Elbow joint pain

Hip pain

Dorsum of foot

Buttocks

Extra-articular sites

Uveitis

Skin rashes

$17(59 \%)$

$15(52 \%)$

$14(48 \%)$

$10(34 \%)$

$05(17 \%)$

$05(17 \%)$

$03(10 \%)$

$02(7 \%)$

$02(7 \%)$

$02(7 \%)$

$15(52 \%)$

$05(17 \%)$

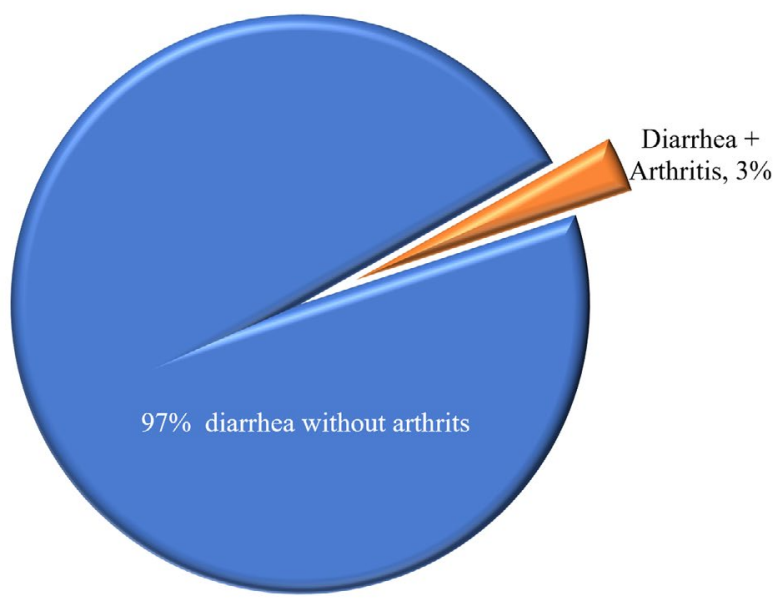

Total diarrhea Sample

口 Diarrhea + Arthritis

Fig. 2. Frequency of Reactive arthritis in Diarrhea patients 
Table 2. Microbiological agents in the gut associated with Reactive arthritis

\begin{tabular}{lcc}
\hline Organisms & $\begin{array}{c}\text { Total } \\
\text { Numbers } \\
(\%)\end{array}$ & $\begin{array}{c}\text { Symptoms of Post } \\
\text { diarrhea \& gut } \\
\text { infection prone } \\
\text { to arthritis }\end{array}$ \\
\hline Escherichia coli & $572(63 \%)$ & 13 \\
Klebsiella species & $126(14 \%)$ & 1 \\
Parasite & $99(11 \%)$ & 0 \\
Proteus vulgaris & $43(5 \%)$ & 1 \\
Proteus mirabilis & $27(3 \%)$ & 0 \\
Salmonella species & $20(2 \%)$ & 13 \\
Enterococcus species & $8(1 \%)$ & 0 \\
Citrobacter species & $8(1 \%)$ & 1 \\
\hline
\end{tabular}

and $99(11 \%)$ patients out of 903 respectively (Fig. 4). The duration between diarrhea and the development of arthritic manifestations was observed to be $\geq 2$ weeks. Pathogenic gut microbes identified from stool samples and their frequencies were as follows: Escherichia coli (572;63\%), Klebsiella species (126; 14\%), Proteus vulgaris (43; $5 \%)$, Proteus mirabilis $(27 ; 3 \%)$, and Citrobacter species and Enterococcus species (8; $1 \%)$. The samples were further probed to determine if they induced $\operatorname{ReA}$ (Table 2). None of the isolated enteric pathogens were found to produce specific resistance in the antimicrobial susceptibility tests. Patients with parasitic etiology presented symptoms of spondyloarthritis post diarrhea. Four enteric pathogens (Escherichia coli,

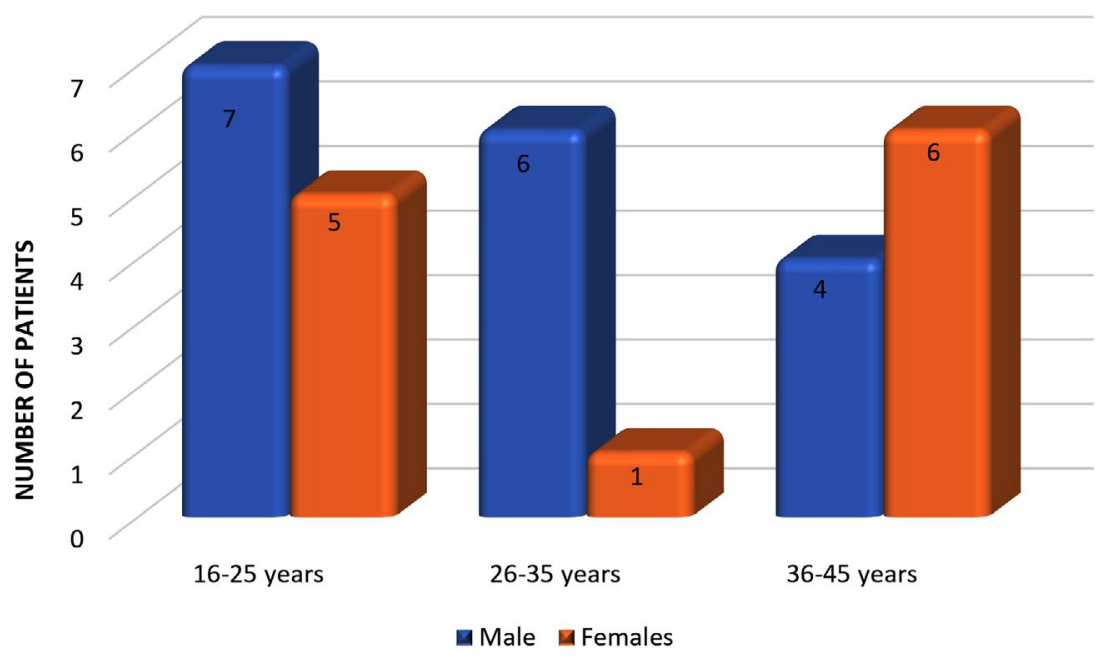

Fig. 3. Distribution of ReA among 29 patients by age and gender

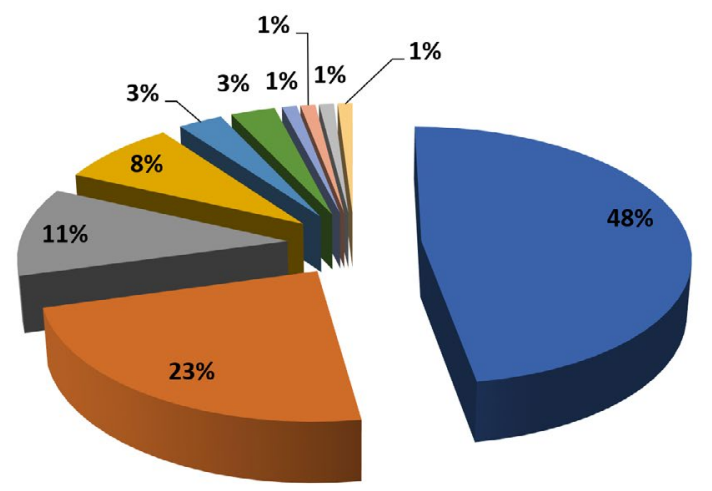

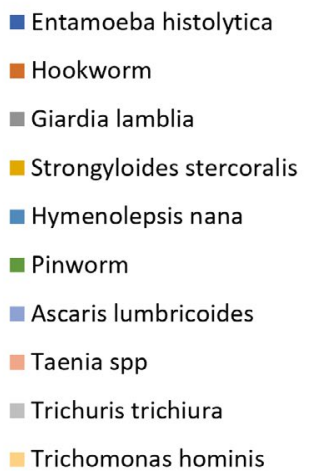

Fig. 4. Distribution of parasitic etiology among patients 
Salmonella spp., Klebsiella spp., Proteus spp., and Citrobacter spp.) were identifiedin all 29 patients presenting with symptoms of spondyloarthritides and post diarrhea (Table 2).

Analysis of CRP and ESR markers in 29 patients revealed that: $17(59 \%)$ patients with active inflammation had raised CRP and ESR levels, $5(17 \%)$ patients had normal levels of CRP and ESR, and $7(24 \%)$ patients had normal levels of ESR but raised CRP levels.

Out of 29 post diarrheal arthritis patients, we identified Salmonella spp. from 13 patients, and further categorized them as HLA-B27 positive(12) and HLA-B27 negative (1).The remaining 16 patients were identified with enteric pathogens including. 13 Escherichia coli, 1 Klebsiella species, 1 Citrobacter species, and 1 Ancylostoma duodenale which triggered ReA without influencing HLA-B27.

\section{DISCUSSION}

Pathogens causing diarrhea may induce molecular mimicry between microbial products and self-antigens, resulting in the activation of auto-reactive lymphocytes, provoking immunological alterations leading to rheumatological manifestations [Schiellerup P. ${ }^{3}$, Keating R.M. ${ }^{7}$, Brocq $0 .{ }^{10}$ ].

We have observed a higher incidence of ReA associated with HLA-B27, 12 out of 20 (41\%) patients were detected with Salmonella infection, which is similar to the results in Schiellerup, et al, 2008 [Schiellerup P. ${ }^{3}$ ], with 6 out of 15 (40\%) Salmonella infections detected with definitive ReA.

Among analysis of various Salmonella outbreak studies by Timo Hannu, $2011^{16}$ \& Ajene AN et. al., $2013^{17}$, before and after the year of 2000 , the frequency of ReA varies greatly ranging from $1.8 \%$ to $15 \%$ and $0.1 \%$ to $29 \%$ respectively. In Arthritis Rheumatology 2000, Ekman P et al. stated that following Salmonella infections, detection of HLA-B27 was associated with increased severity and duration of articular symptoms [Meadow ${ }^{11}$. Sixteen patients had articular and extra-articular manifestations following diarrhea without influencing HLA-B27, caused by non-pathogenic isolates such as Escherichia coli, Klebsiella species, Citrobacter species and Ancylostoma duodenale. These infections may trigger ReA without development of any disease manifestations for long durations, becoming self- limited, thus not requiring treatment [Ekman P. ${ }^{5}$, Meadow ${ }^{11}$.

Ajene et al., $2013^{17}$ noted, that gender does not seem to play a role in ReA associated with enteric infections. Our study, shows a male predominance of $58.6 \%$ contrary to and a study conducted by Schiellerup, et al, $2008^{3}$, which reported an over-presentation of females in the ReA group. Timo Hannu, $2011^{16}$, as supported in various articles, stated that although both adults and children developed ReA, adults were more susceptible to ReA following enteric infection (24\%) compared to children (12\%).

Twenty-nine patients with articular and extra-articular manifestations were followed up and the most commonly reported symptoms were neck pain, knee pain, heel pain and ocular symptoms such as uveitis consistent with the study conducted by Rohekar et.al. in $2008^{13}$, where most patients had joint pain with another symptom such as joint stiffness or ocular symptoms or heel pain. They also observed a high rate of symptoms consistent with ReA particularly in those infected by Salmonella spp.

Garcia-Ktuzbach et al., 2018 ${ }^{12}$, stated that the clinical presentation mainly involves polyarthritis with dactylitis (16\%), sacroiliitis (15-30\%), lower back pain, enthesitis (67\%) and extra articular manifestations such as uveitis, conjunctivitis, Keratoderma blenorrhagicum (KD), urethritis, and diarrhea which shows correspondence to our study which reports a similar clinical picture with sacroiliac inflammation (24\%), lower back pain (41\%), peripheral articular complaints such as knee pain(59\%), heel pain $(52 \%)$, dactylitis (48\%), shoulder pain (34\%) and extra-articular complications such as uveitis (52\%), and Keratoderma blenorrhagicum(17\%).

Arthritis symptoms following diarrhea, is a group of Spondyloarthritis ( $\mathrm{SpA})$, it consist of Psoriatic arthritis (PsA), Ankylosing spondylitis (AS), Reactive arthritis (ReA), Undifferentiated Spondyloarthritis (UnSpA), Childhood Reactive arthritis, and Spondylitis associated with inflammatory bowel disease (IBD).Several studies investigating the association of ReA with HLA-B27 has reported a higher frequency, but at present HLA-B27 cannot be used as a diagnostic tool for detection of ReA, although its presence is associated with a more protracted form of the 
arthritis $^{18}$. ReA in males was more commonly associated with HLA-B27 (83\%) compared to females $(17 \%)$ in our study.

\section{CONCLUSION}

This study highlights the prevalence of HLA-B27 among patients with symptoms of spondyloarthritis post diarrhea. HLA typing may aid in the early diagnosis of ReA before the development of sacroiliitis and other radiological features, which are detected though MRI scan/ X-ray. In our study, we observed that $41.3 \%$ patients with infectious diarrhea were more commonly associated with HLA-B27, articular and extra-articular manifestations, suggestive of ReA triggered by bacterial etiology. The most common bacterial etiology that triggered ReA, was found to be Salmonella spp. (44.8\%) and Escherichia coli (44.8\%).

\section{Recommendations}

HLA-B27 screening can aid in early diagnosis and treatment of spondyloarthritides, in young patients and can be useful to check other family members for spondyloarthritides as well. HLA typing can be used to exclude the other causes of inflammatory arthritis. Mandatory screening of HLA-B27 in young patients can prevent the genetic transmission to the future generation.

\section{ACKNOWLEDGMENTS}

We would like to express our sincere gratitude to Dr. Arul Raja Murugan M.D., DM., Assistant Professor of Rheumatology, for his support in writing the manuscript and acknowledge the continuous assistance provided by our lab technicians, Mrs. Sowmyalaksmi N. and Mrs. Srividhya throughout the study period.

\section{CONFLICT OF INTEREST} conflict of interest.

The authors declare that there is no

\section{AUTHORS' CONTRIBUTION}

All authors listed have made a substantial, direct and intellectual contribution to the work, and approved it for publication.

\section{FUNDING}

None.

\section{DATA AVAILABILITY}

All datasets generated or analyzed during this study are included in the manuscript.

\section{ETHICS STATEMENT}

This study was approved from the institute's ethical committee, SRM Medical College Hospital and Research Centre with wide Reference No: $1209 /$ IEC/2017.

\section{INFORMED CONSENT}

An informed consent document was obtained from all the patients.

\section{REFERENCES}

1. Mustafa Serdar SA TI, Sinem SA. Reactive arthritis. Medicine Science. 2016;5(4):7.

2. Colmegna I CR, Espinoza LR. HLA-B27-associated reactive arthritis: pathogenetic and clinical considerations. Clin Microbiol Rev. 2004;17(2):348369. doi: 10.1128/CMR.17.2.348-369.2004

3. Schiellerup P KK, Locht H. A comparison of selfreported joint symptoms following infection with different enteric pathogens; effect of HLA-B27. Journal of Rheumatology. 2008;35:7.

4. Connor BA, Riddle MS. Post-infectious sequelae of travelers' diarrhea. J Travel Med. 2013;20(5):303-312. doi: 10.1111/jtm.12049

5. Ekman PKJ, Granfors K. Modification of disease outcome in Salmonella infected patients by HLA-B27. Arhtritis Rheum. 2000;43(7):1527-1534. doi: 10.1002/1529-0131(200007)43:7<1527::AIDANR17>3.0.CO;2-G

6. Buret $A G$, Reti $K$. Acute enteric infections alter commensal microbiota: new mechanisms in postinfectious intestinal inflammatory disorders. In Old Herborn University Seminar Monograph: Persisting Consequences of Intestinal Infection 2014;27:87-106.

7. Keating RM Vyas AS. Reactive arthritis following Clostridium difficile colitis. West J Med. 1995;162(1):6163. PMID: 7863666

8. Boice JL. Reactive arthritis induced by Clostridium difficile. West J Med. 1994;160(2):171-172. PMID: 8160472

9. Woo P, Panayi GS. Reactive arthritis due to infestation with Giardia lamblia. J Rheumatol. 1984;11(5):719. PMID: 6512798

10. Brocq O, Breuil V, Agopian V, et al. Reactive arthritis induced by Strongyloides stercoralis. Rev Rheum Engl Ed. 1996;63(3):217-219. PMID: 8731241

11. Meadow WL, Schneider H, Beem O. Salmonella enteritidis bacteremia in childhood". J Infect Dis. 1985;152(1):185-189. doi: 10.1093/infdis/152.1.185

12. Garcia-Kutzbach A, Chacon-Suchite J, Garcia-Ferrer $\mathrm{H}$, Iraheta I. Reactive arthritis: update 2018. Clin Rheumatol. 2018;37(4):869-874. doi: 10.1007/s10067018-4022-5

13. Rohekar S, Tsui FWL, Tsui HW, et al. Symptomatic acute 
reactive arthritis after an outbreak of Salmonella. J Rheumatol. 2008;35(8):1599-1602. PMID: 18528961

14. Fendler $\mathrm{C}$, Laitko $\mathrm{S}$, Sorensen $\mathrm{H}$, et al. Frequency of triggering bacteria in patients with reactive arthritis and undifferentiated oligoarthritis and the relative importance of the test used for diagnosis. Ann Rheum Dis. 2001;60(4):337-343. doi: 10.1136/ard.60.4.337

15. Harrison. HARRISON'S Principles of INTERNAL MEDICINE 2:86.

16. Hannu T. Reactive arthritis. Best Pract Res Clin Rheumatol. 2011;25(3):347-357. PMID: 22100285

17. Ajene AN, Walker CLF, Black RE. Enteric pathogens and reactive arthritis: a systematic review of Campylobacter, Salmonella and Shigella associated reactive arthritis. J Health Popul Nutr. 2013;31(3):299307. doi: 10.3329/jhpn.v31i3.16515

18. Khan MA. Polymorphism of HLA-B27: 105 subtypes currently known. Curr Rheumatol Rep. 2013;15(10):362. doi: 10.1007/s11926-013-0362-y
19. Humphries RM, Linscott AJ. Practical Guidance for Clinical Microbiology Laboratories: Laboratory diagnosis of bacterial gastroenteritis. Clin Microbiol Rev. 2015;28(1):3-31. doi: 10.1128/CMR.00073-14

20. Garcia LS, Arrowood M, Kokoskin E, et al. Laboratory diagnosis of parasites from the gastrointestinal tract. Clin Microbiology Rev. 2018;31(1):e00025-17. doi: 10.1128/CMR.00025-17

21. Sanchez-Romero MI, Moya JMG-L, Lopez JJG, Mira NO. Collection, transport and general processing of clinical specimens in Microbiology laboratory. Enfermedades infecciosas y microbiologia clinica (English ed). 2019;37(2):127-134. doi: 10.1016/j. eimce.2017.12.005

22. Kotgire SA. Microbiological stool examination: Overview. J Clin Diagn Res. 2012;6(3):503-509.

23. Qadri SM, Zubairi S, Hawley HP, Mazlaghani HH, Ramirez EG. Rapid test for determination of urea hydrolysis. Antonie van Leeuwenhoek. 1984;50(4):417423. doi: 10.1007/BF00394656 